\title{
Instability of Amorphous Ru-Si-O Thin Films under Thermal Oxidation
}

\author{
S. M. Gasser, ${ }^{\mathrm{Z}}$ R. Ruiz, E. Kolawa, and M.-A. Nicolet
}

California Institute of Technology, Pasadena, California 91125, USA

Ternary films about $200 \mathrm{~nm}$ thick of composition $\mathrm{Ru}_{20} \mathrm{Si}_{15} \mathrm{O}_{65}$ have been synthesized by reactive rf magnetron sputtering of a $\mathrm{Ru}_{1} \mathrm{Si}_{1}$ target in an argon-oxygen gas. As-deposited, the films are X-ray-amorphous. Their atomic density is $8.9 \times 10^{22} / \mathrm{cm}^{3}$ $\left(5.1 \mathrm{~g} / \mathrm{cm}^{3}\right)$, and their electrical resistivity is in the range of $2 \mathrm{~m} \Omega \mathrm{cm}$. After annealing in dry oxygen at $600^{\circ} \mathrm{C}$ for $30 \mathrm{~min}$, micronsized grains of $\mathrm{RuO}_{2}$ grow out of the film and volatile $\mathrm{RuO}_{4}$ escapes. The significance of these results is discussed. (C) 1999 The Electrochemical Society. S0013-4651(98)07-010-4. All rights reserved.

Manuscript received July 6, 1998.

Ternary thin films of the type TM-Si-N, where TM are transition metals of the $\mathrm{Ti}, \mathrm{V}$, and $\mathrm{Cr}$ groups, have properties that are both scientifically interesting and practically useful. Depending on their mode of deposition, on their composition, and on their postannealing treatment, they can be structurally amorphous down to highresolution transmission electron microscopy (TEM-amorphous), nanostructured so as to appear amorphous under X-ray diffraction (X-ray-amorphous), or polycrystalline with varying grain sizes. They can be single-phase or two-phase structured, electrically insulating or conducting. A recent compilation of the relevant literature is given in Ref. 1-3. Uses where one or several unique properties of these films are exploited have been demonstrated in applications as various as a primary mask for X-ray lithography, ${ }^{4}$ thin-film diffusion barriers in semiconductor metallizations, ${ }^{5-8}$ ultrahard coatings, ${ }^{9-12}$ and micromachining. ${ }^{13}$

Motivated by these successes, we have asked whether analogous ternary thin films of the type TM-Si-O could be synthesized with properties that might be similarly useful and interesting. This paper presents the first results and answers to this question.

Specifically, we asked if amorphous ternary films of $\mathrm{Ru}-\mathrm{Si}-\mathrm{O}$ could be obtained by reactive sputtering a $\mathrm{Ru}_{1} \mathrm{Si}_{1}$ target. This choice follows the line of thought that leads to amorphous TM-Si-N films. These alloys may be viewed as a combination of a metallically conducting binary transition metal nitride (such as TiN, that has a simple B1 crystal structure) with $\mathrm{Si}_{3} \mathrm{~N}_{4}$, an insulating nitride with a predilection for an amorphous structure, to produce a TM-Si-N film (such as Ti-Si-N). $\mathrm{RuO}_{2}$ is a metallically conducting oxide that has a simple C4 structure, and $\mathrm{SiO}_{2}$ is an insulating oxide that typically forms amorphous films. In analogy with TiN and $\mathrm{Si}_{3} \mathrm{~N}_{4}, \mathrm{RuO}_{2}$ and $\mathrm{SiO}_{2}$ may thus also yield amorphous ternary $\mathrm{Ru}-\mathrm{Si}-\mathrm{O}$. Underlying this approach is the concept that a combination of species that normally solidify in different crystalline structures will frustrate the system and induce the formation of an amorphous phase. And, in addition, the combination of a predominantly metallically bonded species with one that is predominantly covalently bonded will similarly favor that outcome. The validity of that approach is underscored by the results obtained with the TM-Si-N alloys, some of which remain X-rayamorphous up to heat-treatments of $950^{\circ} \mathrm{C}$ for $30 \mathrm{~min}$ in vacuum..$^{5}$

In the present investigation we address two particular questions about the Ru-Si-O alloy system: (i) Is it possible to obtain amorphous films by reactive sputtering of a ruthenium silicide target in an oxidizing ambient, as has been successfully done with the reactive sputtering of early transition metal silicides in a nitrogen-carrying ambient? (ii) If so, how stable are the amorphous films thus obtained upon thermal annealing? For the latter investigation, we have chosen thermal treatments in an oxidizing ambient because ruthenium can form the volatile compound ruthenium tetroxide $\left(\mathrm{RuO}_{4}\right)$. In contrast to annealing in vacuum, this treatment tests the stability of the resulting film both structurally as well as chemically under conditions near those encountered in practice by coatings. Amorphous conduct-

\footnotetext{
z E-mail: sgasser@cco.caltech.edu
}

ing oxides may offer practical advantages in applications in corrosive media.

\section{Experimental}

Silicon wafers covered with thermally grown $\mathrm{SiO}_{2}$ of $120 \mathrm{~nm}$ thickness served as substrate for this study. Thin films of Ru-Si-O were deposited by reactive $\mathrm{rf}(13.56 \mathrm{MHz})$ sputtering with argon as sputtering gas and oxygen as reactant in a cryopumped vacuum system of $5 \times 10^{-7}$ Torr base pressure. A net forward sputtering power of $300 \mathrm{~W}$ was applied on a $\mathrm{Ru}_{1} \mathrm{Si}_{1}$ target $3 \mathrm{in}$. in diam, and the samples were centrally positioned $13 \mathrm{~cm}$ below the circular target. No bias was applied, neither was the sample actively heated or cooled, and the substrate temperature is estimated to stay below $100^{\circ} \mathrm{C}$ during the deposition. Selected samples were patterned by drawing stripes on the oxide surface with a conventional felt-tip pen and liftoff with acetone after the deposition to measure the thickness of the sputtered layers with a stylus profilometer. The samples were then annealed in an open quartz-tube furnace and a dry oxygen flow of $80 \mathrm{~cm}^{3} / \mathrm{min}$ at 600 and $800^{\circ} \mathrm{C}$. Elemental depth profiles were measured with $2.0 \mathrm{MeV}^{4} \mathrm{He}^{2+}$ backscattering spectrometry, and atomic composition were extracted from them with an overall accuracy level of approximately 5\%. Sheet resistance measurements were performed with a four-point probe. Structural information was obtained by Debye-Scherrer X-ray diffraction with a collimated Co K $\alpha$ beam incident on the sample at a glancing angle of $12^{\circ}$ and an Inel position-sensitive detector. Scanning electron micrographs were taken on a Cambridge Stereoscan $250 \mathrm{Mk} 2$ with a Kevex energy-dispersive spectrometer. The beam spot for energy-dispersive X-ray mapping has a diameter of $83 \mathrm{~nm}$. To test whether some volatile ruthenium tetroxide $\left(\mathrm{RuO}_{4}\right)$ evolves, an oxygen-saturated $\mathrm{Ru}-\mathrm{Si}-\mathrm{O}$ film was sealed into a Pyrex test tube in ambient air and annealed at $600^{\circ} \mathrm{C}$ for $60 \mathrm{~min}$. The test tube was subsequently positioned in a HP 8452A diode array spectrophotometer in such a way that the beam traversed the test tube walls, any deposits on them, and the enclosed gas without seeing the sample that was lying on the bottom of the sealed test tube. The absorption spectrum was measured before and after the heat-treatment.

\section{Results}

Partial flow rates of oxygen from 0 to $10 \%$ were employed for the reactive sputtering of the $\mathrm{Ru}-\mathrm{Si}-\mathrm{O}$ thin films from the $\mathrm{Ru}_{1} \mathrm{Si}_{1}$ target. Depending on the oxygen partial flow, sputtering rates between 130 and $250 \AA / \mathrm{min}$ are achieved. The atomic concentration of oxygen in the film reaches a saturation value of about 65 atom $\%$ at a partial flow rate of oxygen above $6 \%$. This value is expected if $\mathrm{RuO}_{2}$ and $\mathrm{SiO}_{2}$ are to be the only and stable binary reaction products of the sputtering process. $\mathrm{SiO}_{2}$ is well known to favor the formation of amorphous films. We observe that our films are X-ray amorphous when the oxygen atomic composition nears saturation, above $55 \%$.

The samples that are used for further investigations in this study are all oxygen-saturated. After deposition, their atomic density is $8.9 \times 10^{22} / \mathrm{cm}^{3}\left(5.1 \mathrm{~g} / \mathrm{cm}^{3}\right)$, and their electrical resistivity is in the range of $2 \mathrm{~m} \Omega \mathrm{cm}$. Figure 1 shows the $\mathrm{X}$-ray diffraction spectra of a 


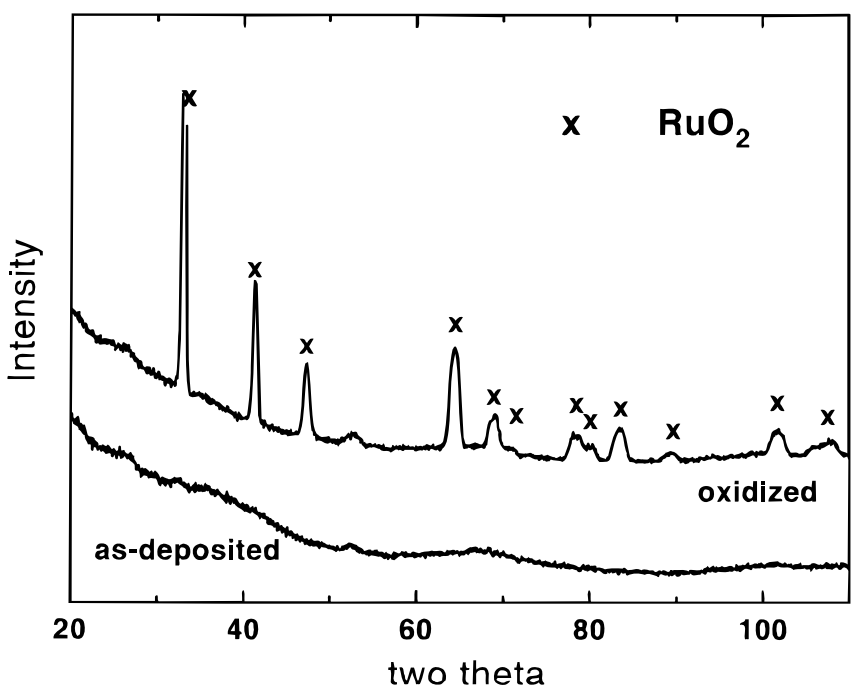

Figure 1. Diffraction spectra of a $200 \mathrm{~nm}$ thick $\mathrm{Ru}_{20} \mathrm{Si}_{15} \mathrm{O}_{65}$ film deposited on a $120 \mathrm{~nm}$ thick $\mathrm{SiO}_{2}$ covered $\mathrm{Si}$ wafer, taken with $\mathrm{Co} \mathrm{K \alpha} \mathrm{X}$-rays before and after oxidation at $600^{\circ} \mathrm{C}$ for $30 \mathrm{~min}$.

$200 \mathrm{~nm}$ thick $\mathrm{Ru}_{20} \mathrm{Si}_{15} \mathrm{O}_{65}$ film before and after annealing in dry oxygen at $600^{\circ} \mathrm{C}$ for $30 \mathrm{~min}$. No diffraction peaks are observed from the as-deposited sample, but clear peaks emerge after oxidation. They can all be assigned to $\mathrm{RuO}_{2}$. Peaks of $\mathrm{SiO}_{2}$ are not detected.

The annealing also dramatically changes the backscattering spectra of the films. Figure 2 compares $2 \mathrm{MeV} \mathrm{He}^{2+}$ backscattering spectra of films annealed at $800^{\circ} \mathrm{C}$ for 5,15 , and $30 \mathrm{~min}$ with the spectrum of the as-deposited film. One interpretation of these spectra is that ruthenium has diffused deeply into the substrate. Another is that thick columnar features containing ruthenium have grown on or through the surface. A decrease of the total counts in the ruthenium signal upon annealing is indicated and leads to the suspicion that some ruthenium might have been lost during the oxidation process. Ruthenium tetroxide $\left(\mathrm{RuO}_{4}\right)$ starts to volatilize noticeably ${ }^{14}$ at $7^{\circ} \mathrm{C}$, has a very low melting point ${ }^{15}$ of $25.5^{\circ} \mathrm{C}$ and a boiling point ${ }^{16}$ of $129.6^{\circ} \mathrm{C}$. If $\mathrm{RuO}_{4}$ were formed during the oxidation, it would be volatile and lead to the loss of ruthenium from the film.

We proved the formation of $\mathrm{RuO}_{4}$ by light absorption spectroscopy. Small samples were sealed under ambient air in a Pyrex (borosilicate glass) test tube, and the test tube was annealed at $600^{\circ} \mathrm{C}$

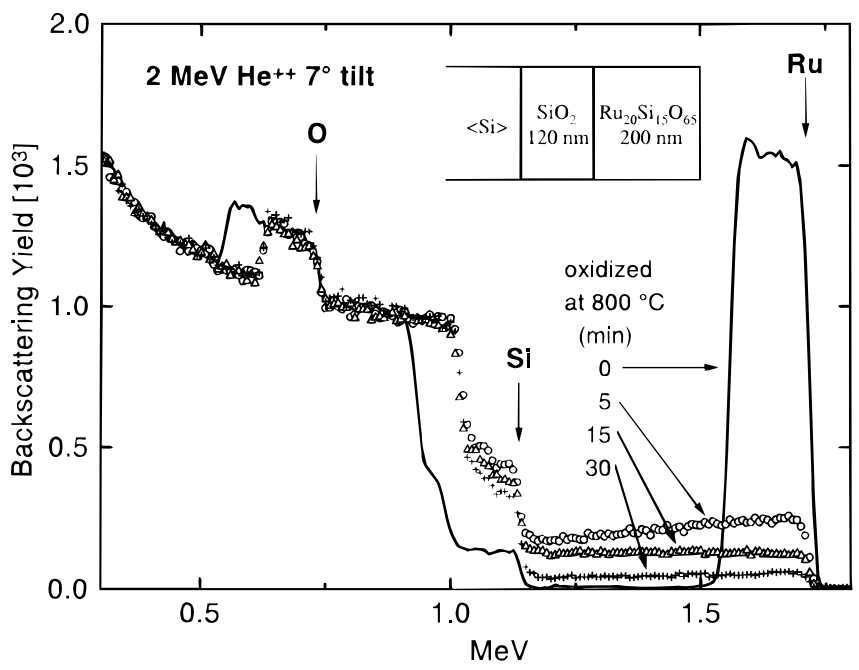

Figure 2. $2.0 \mathrm{MeV} 4 \mathrm{He}^{2+}$ backscattering spectra of a $200 \mathrm{~nm}$ thick $\mathrm{Ru}_{20} \mathrm{Si}_{15} \mathrm{O}_{65}$ film deposited on a $120 \mathrm{~nm}$ thick $\mathrm{SiO}_{2}$-covered $\mathrm{Si}$ wafer, before and after oxidation at $800^{\circ} \mathrm{C}$ for 5,15 , and $30 \mathrm{~min}$.

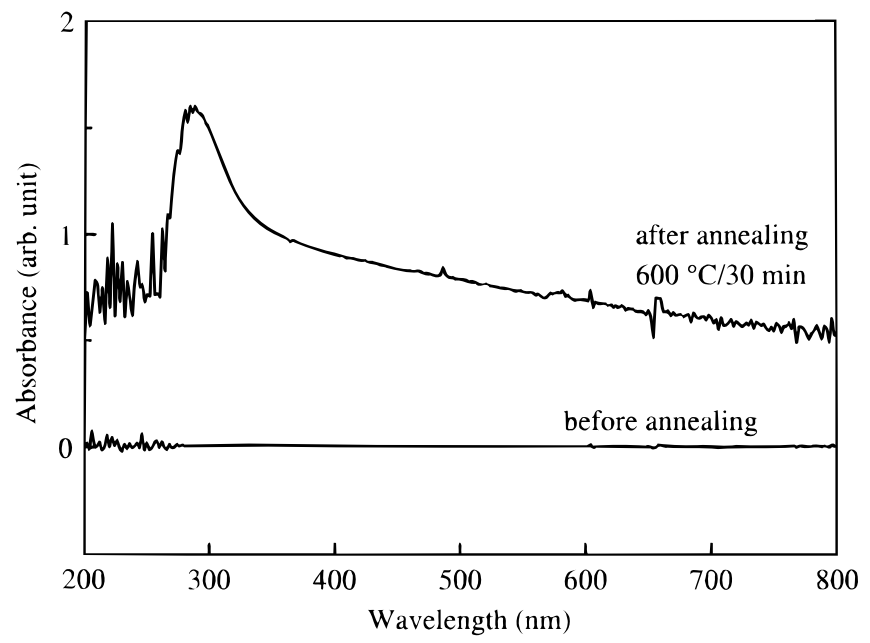

Figure 3. Light absorption spectra of the walls of a test tube that contained a $200 \mathrm{~nm}$ thick $\mathrm{Ru}_{20} \mathrm{Si}_{15} \mathrm{O}_{65}$ film deposited on a $120 \mathrm{~nm}$ thick $\mathrm{SiO}_{2}$-covered $\mathrm{Si}$ wafer, obtained at room temperature before and after annealing at $600^{\circ} \mathrm{C}$ for $30 \mathrm{~min}$.

for $30 \mathrm{~min}$. The amount of oxygen enclosed in the test tube was sufficient to form $\mathrm{RuO}_{4}$ with all the ruthenium contained in the thin film. Signs of material removal from the $\mathrm{Ru}-\mathrm{Si}-\mathrm{O}$ thin film are already seen visually by noticing that after annealing the walls of the test tube are coated with a diffuse milky layer. Figure 3 shows the absorption spectra, taken at room temperature, of the test tube before and after annealing. A clear absorption peak can be seen after annealing with its maximum around $290 \mathrm{~nm}$. A main absorption maximum at $310 \mathrm{~nm}$ for $\mathrm{RuO}_{4}$ (oxidation state $\left.\mathrm{d}^{0}\right)^{17}$ has been published by Wells et al., ${ }^{18}$ while the reflectance spectrum for $\mathrm{RuO}_{2}$ (oxidation state $\left.\mathrm{d}^{4}\right)^{17}$ is reported to exhibit a broad band from 430 to $700 \mathrm{~nm}$, centered at $585 \mathrm{~nm} .{ }^{19}$ Accounting for the width of the peak and the resolution of the spectrometer, our result clearly proves the presence of $\mathrm{RuO}_{4}$ on the walls of the test-tube and thus the loss of ruthenium from the film during annealing in dry oxygen at $600^{\circ} \mathrm{C}$.

A scanning electron micrograph (SEM) of the surface of a $\mathrm{Ru}_{20} \mathrm{Si}_{15} \mathrm{O}_{65}$ thin film, after oxidation at $600^{\circ} \mathrm{C}$ for $30 \mathrm{~min}$, is shown in Fig. 4. Predominantly columnar-shaped crystallites with dimensions of about $5 \mu \mathrm{m}$ in length and $1 \mu \mathrm{m}$ in diameter can be observed, sticking out of a flat surface and perhaps partly embedded in it. Surface mapping by two-dimensional energy-dispersive analysis of in-

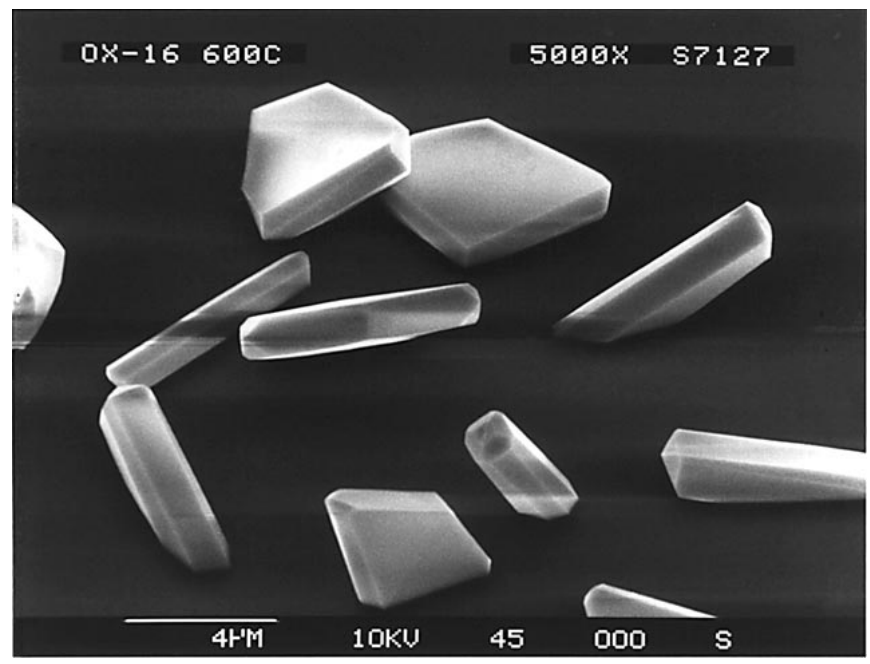

Figure 4. Scanning electron micrograph of a $200 \mathrm{~nm}$ thick $\mathrm{Ru}_{20} \mathrm{Si}_{15} \mathrm{O}_{65}$ film deposited on a $120 \mathrm{~nm}$ thick $\mathrm{SiO}_{2}$-covered $\mathrm{Si}$ wafer, after oxidation at $600^{\circ} \mathrm{C}$ for $30 \mathrm{~min}$ 
duced X-rays reveals that all the ruthenium is concentrated in the crystallites while silicon is found only in the surrounding matrix. Oxygen can be observed everywhere. Together with the X-ray data, these facts indicate that the crystallites are $\mathrm{RuO}_{2}$. The remainder is a film of $\mathrm{SiO}_{2}$, possibly containing some residual ruthenium oxide. The backscattering spectra of Fig. 2 are consistent with this picture. SEMs of as-deposited films on the same scale as Fig. 4 are featureless. The electrical resistivity of that film is too high to be measurable by a four-point probe.

\section{Discussion and Conclusion}

The synthesis of amorphous ternary films of composition $\mathrm{Ru}_{20} \mathrm{Si}_{15} \mathrm{O}_{65}$ is demonstrated and confirms the idea that the combination of metallically conducting $\mathrm{RuO}_{2}$ with covalently bonded $\mathrm{SiO}_{2}$ leads to the formation of amorphous ternary $\mathrm{Ru}-\mathrm{Si}-\mathrm{O}$ thin films. Their electrical resistivity of about $2 \mathrm{~m} \Omega \mathrm{cm}$ (bulk resistivity of $\mathrm{RuO}_{2}: 35 \mathrm{~m} \Omega \mathrm{cm}$ ) together with the X-ray amorphous structure makes such films acceptable candidates for applications with moderate temperature requirements.

$\mathrm{RuO}_{2}$ is used for thin- ${ }^{21}$ and thick-film resistors, ${ }^{22,23}$ as well as for coatings on electrodes. ${ }^{24,25}$ Interest has recently risen for $\mathrm{RuO}_{2}$ films as electrodes for ferroelectric barium-strontium-titanate (BST), ${ }^{26,27}$ and lead-zirconate-titanate (PZT), ${ }^{28,29}$ thin films to make nonvolatile memory elements. Films of $\mathrm{RuO}_{2}$ have also been considered for metallizations in integrated circuits. ${ }^{30-35}$ The values of the heats of formation of the transition metal oxides are comparable to those of the transition metal nitrides and indicate good thermal stability. ${ }^{36}$ The surface morphology of $\mathrm{RuO}_{2}$ films is reported to remain smooth after rapid thermal annealing up to $900^{\circ} \mathrm{C}$ for $10 \mathrm{~s}$ in argon, nitrogen, and oxygen. ${ }^{37}$

On the other hand, Green et al. report that $\mathrm{RuO}_{2}$ films disproportionate and decompose to ruthenium and volatile $\mathrm{RuO}_{4}$ upon annealing in vacuum at $900^{\circ} \mathrm{C}$ for $2 \mathrm{~h}$, according to the reaction $2 \mathrm{RuO}_{2} \rightarrow$ $\mathrm{Ru}+\mathrm{RuO}_{4} \cdot{ }^{34}$ Using the process $\mathrm{RuO}_{4} \rightarrow \mathrm{RuO}_{2}+\mathrm{O}_{2}$, Yuan et al. synthesized $\mathrm{RuO}_{2}$ films from $\mathrm{RuO}_{4}$ by chemical vapor deposition. ${ }^{38}$ In our present situation, annealing of the $\mathrm{Ru}_{20} \mathrm{Si}_{15} \mathrm{O}_{65}$ films occurred in an open system and a dry oxygen ambient at atmospheric pressure where the supply of oxygen was unlimited. Rather than the decomposition of $\mathrm{RuO}_{2}$ films to $\mathrm{Ru}$ and volatile $\mathrm{RuO}_{4}$, we observe the formation of volatile $\mathrm{RuO}_{4}$ and growth of $\mathrm{RuO}_{2}$ crystallites, which is the reverse of the process described by Yuan et al. The growth of $\mathrm{RuO}_{2}$ particles in bulk glasses was studied previously by Nakano et al.: starting with $10 \mathrm{vol} \% \mathrm{RuO}_{2}$ grains of around $15 \mathrm{~nm}$ average size dissolved in glass, extensive growth is observed only at $950^{\circ} \mathrm{C}$ with a particle size of $60 \mathrm{~nm}$ after $1 \mathrm{~h} .{ }^{39}$ In contrast, our oxygen-saturated ternary $\mathrm{Ru}-\mathrm{Si}-\mathrm{O}$ thin films separate into $\mathrm{RuO}_{2}$ crystals and a surrounding $\mathrm{SiO}_{2}$ matrix much more rapidly, accompanied by the evolution of volatile $\mathrm{RuO}_{4}$. As indicated through the backscattering spectrum, major changes are observable already after $5 \mathrm{~min}$ at $800^{\circ} \mathrm{C}$. A reaction process based on the gaseous phases of oxygen and $\mathrm{RuO}_{4}$ appears to be most likely. Atomic oxygen has been found to etch $\mathrm{RuO}_{2}$ to form volatile $\mathrm{RuO}_{4}$ products. ${ }^{17}$ Other reaction processes might also be involved, since the catalytic power of ruthenium complexes is well known and used in many other fields such as solar energy conversion, ${ }^{40}$ coordination chemistry, ${ }^{41,42}$ and biochemical applications. ${ }^{43,44}$

The answers to the two questions posed initially are therefore that $(i)$ it is possible to obtain $\mathrm{X}$-ray-amorphous $\mathrm{Ru}_{20} \mathrm{Si}_{15} \mathrm{O}_{65}$ alloys by reactive sputtering of $\mathrm{RuSi}$, but (ii) the alloys are unstable in an oxidizing ambient, at a time/temperature exposure of $30 \mathrm{~min}$ at $600^{\circ} \mathrm{C}$, or less. Our results from treatment of $\mathrm{Ru}_{20} \mathrm{Si}_{15} \mathrm{O}_{65}$ films in oxidizing ambient do not preclude that the same films could be thermally stable in an inert ambient or vacuum. This aspect would deserve further attention.

\section{Acknowledgments}

Dr. Martina Hüber established the connection with Dr. Harry Gray, who suggested light absorption spectroscopy to identify $\mathrm{RuO}_{4}$. The authors express their appreciation to them for helpful discussions. Technical assistance from Rob Gorris is gratefully acknowledged. Financial support for this study was provided by the Center for Integrated Space Microsystems at JPL/NASA and is gratefully acknowledged.

California Institute of Technology assisted in meeting the publication costs of this aricle.

\section{References}

1. M.-A. Nicolet, Defect Diffus. Forum, 143, 1271 (1997).

2. M.-A. Nicolet, Appl. Surf. Sci., 91, 269 (1995).

3. R. de Reus, in Intermetallic Compounds, Vol. 2, Practice, p. 603, J. H. Westbrook and R. L. Fleischer, Editors, John Wiley \& Sons, Chicester, England (1994).

4. W. J. Dauksher, D. J. Resnick, K. D. Cummings, J. Baker, R. B. Gregory, N. D. Theodore, J. A. Chan, W. A. Johnson, C. J. Mogab, M.-A. Nicolet, and J. S. Reid, J. Vac. Sci. Technol. B, 13, 3103 (1995).

5. J. S. Reid, Ph.D. Thesis, California Institute of Technology, Pasadena, CA (1995).

6. J. S. Reid, E. Kolawa, C. M. Garland, M.-A. Nicolet, F. Cardone, D. Gupta, and R. P. Ruiz, J. Appl. Phys., 79, 1109 (1996).

7. X. Sun, Ph.D. Thesis, California Institute of Technology, Pasadena, CA (1997).

8. X. Sun, J. S. Reid, E. Kolawa, and M.-A. Nicolet, J. Appl. Phys., 81, 664 (1997)

9. S. Veprek, S. Reiprich, and S. H. Li, Appl. Phys. Lett., 66, 2640 (1995).

10. S. Veprek and S. Reiprich, Thin Solid Films, 268, 64 (1995).

11. S. Veprek, M. Haussmann, and S. Reiprich, J. Vac. Sci. Technol. A, 14, 46 (1996).

12. S. Veprek, M. Haussmann, S. Reiprich, L. Shizhi, and J. Dian, Surf. Coat. Technol., 87-8, 394 (1996).

13. C. Linder, A. Dommann, G. Staufert, and M.-A. Nicolet, Sens. Actuators A, 61, 387 (1997).

14. N. V. Sidgwick, Chemical Elements and Their Compounds, Vol. 2, Clarendon Press, Oxford (1950).

15. A. B. Nikol'skii and A. N. Ryabov, Russ. J. Inorg. Chem., 9, 3 (1964).

16. Y. Koda, J. Chem. Soc., Chem. Commun., 17, 1347 (1986).

17. W. Pan and S. B. Desu, Phys. Status Solidi A, 161, 201 (1997).

18. E. J. Wells, A. D. Jordan, D. S. Alderice, and I. G. Ross, Aust. J. Chem., 20, 2315 (1967).

19. J. M. Fletcher, W. E. Gardner, B. F. Greenfield, M. J. Holdoway, and M. H. Rand, J. Chem. Soc. A, 653 (1968).

20. W. D. Ryden and A. W. Lawson, Phys. Rev. B, 1, 1494 (1970).

21. Q. X. Jia, K. L. Jiao, W. A. Anderson, and F. M. Collins, Mater. Sci. Eng. B, 18, 220 (1993).

22. K. M. Yi, K. W. Lee, K. W. Chung, W. S. Um, H. S. Lee, J. K. Song, and I. S. Lee, J. Mater. Sci. Mater. Electron., 8, 247 (1997).

23. G. V. Planer and L. S. A. Phillips, Thick Film Circuits, p. 48, Butterworths, London (1972).

24. I. M. Kodintsev, S. Trasatti, M. Rubel, A. Wieckowski, and N. Kaufher, Langmuir, 8, 283 (1992).

25. S. Trasatti, Electrodes of Conductive Metallic Oxides, Elsevier, Amsterdam (1980)

26. D. K. Choi, J. Y. Won, and S. H. Paek, Mater. Res. Soc. Symp. Proc., 433, 45 (1996).

27. W. Jo, D. C. Kim, H. M. Lee, and K. Y. Kim, Mater. Res. Soc. Symp. Proc., 433, 45 (1996).

28. D. P. Vijay and S. B. Desu, J. Electrochem. Soc., 140, 2640 (1993)

29. H. N. AlShareef, K. R. Bellur, O. Auciello, and A. I. Kingon, Thin Solid Films, 256, 73 (1995).

30. C. W. Nieh, E. Kolawa, F. C. T. So, and M.-A. Nicolet, Mater. Lett., 6, 177 (1988)

31. E. Kolawa, C. W. Nieh, F. C. T. So, and M.-A. Nicolet, J. Electron. Mater, 17, 425 (1988).

32. E. Kolawa, F. C. T. So, W. Flick, X. A. Zhao, E. T. S. Pan, and M.-A. Nicolet, Thin Solid Films, 173, 217 (1989).

33. L. Krusin-Elbaum, M. Wittmer, and D. S. Yee, Appl. Phys. Lett., 50, 1879 (1987).

34. M. L. Green, M. E. Gross, L. E. Papa, K. J. Schnoes, and D. Brasen, J. Electrochem. Soc., 132, 2677 (1985).

35. H. Kezuka, R. Egerton, M. Masui, T. Wada, T. Ikehata, H. Mase, and M. Takeuchi, Appl. Surf. Sci., 65, 293 (1993).

36. L. Krusin-Elbaum, M. Wittmer, C. Y. Ting, and J. J. Cuomo, Thin Solid Films, 104, $81(1983)$.

37. T. S. Kalkur and Y. C. Lu, Thin Solid Films, 205, 266 (1991).

38. Z. Yuan, R. J. Puddenphatt, and M. Sayer, Chem. Mater, 5, 908 (1993).

39. T. Nakano, K. Suzuki, and T. Yamaguchi, J. Adhesion, 46, 131 (1994).

40. R. Ramaraj and M. Kaneko, Adv. Polym. Sci., 123, 215 (1995)

41. J. W. Buchler, C. Dreher, and F. M. Kunzel, Struct. Bonding, 84, 1 (1995)

42. Comprehensive Coordination Chemistry, Vol. 4, G. Wilkinson, R. D. Gillard, and J. A. McCleverty, Editors, p. 277, Pergamon Press, New York (1987).

43. B. R. James, Catal. Today, 37, 209 (1997).

44. M. Murakami and Y. Ito, J. Synth. Org. Chem. Jpn., 55, 444 (1997). 